\title{
Coronary endothelial dysfunction as a predictor of intimal thickening in the long term after heart transplantation
}

\author{
Vicens Martí, MD \\ Isabel Romeo, MD \\ Rosa Aymat, MD \\ Joan García, MD \\ Pere Guiteras, MD \\ Manel Ballester, MD \\ Nasrin Aminian, MD \\ Josep M. Caralps, MD \\ Josep M. Augé, MD
}

From the Departments of Cardiology and Surgery, Hospital de la Santa Creu i Sant Pau, Barcelona, Spain.

Received for publication Jan 18, 2001; revisions requested March 29, 2001; revisions received April 24, 2001; accepted for publication June 5, 2001.

Work supported by Fundación María Francisca de Roviralta and the Fondo de Investigaciones Sanitarias de la Seguridad Social (FISS) grant No. 950801.

Address for reprints: Vicens Martí, MD, Hemodynamic and Cardiologic Interventional Unit, Hospital de la Santa Creu i Sant Pau, Sant Antoni M. Claret 167, 08025 Barcelona, Spain (E-mail: 18461vmc@comb.es).

J Thorac Cardiovasc Surg 2001;122:1174-80

Copyright (C) 2001 by The American Association for Thoracic Surgery

$0022-5223 / 2001 \$ 35.00+0 \quad \mathbf{1 2} / \mathbf{1} / \mathbf{1 1 7 8 3 6}$

doi: $10.1067 / \mathrm{mtc} .2001 .117836$
Objectives: The mechanisms of cardiac allograft vasculopathy and its predisposing factors are multifactorial and as yet not well established. To determine the influence of endothelial dysfunction on the development of intimal thickening, we prospectively analyzed the vasomotor response to acetylcholine and nitroglycerin, as well as other donor and recipient variables. Findings were correlated with the coronary intimal thickness, which was evaluated by means of intravascular ultrasonography.

Methods: Nineteen patients who had undergone heart transplantation $4.89 \pm 2.35$ years previously and who had angiographically normal coronary arteries were included. Endothelial function was analyzed by quantitative coronary analysis of the vasomotor response of the left anterior descending artery to acetylcholine. An intimal thickness index, reflecting the percentage of intima obstructing the coronary lumen, was calculated.

Results: Nine (47\%) patients showed endothelial dysfunction, and the remaining 10 (53\%) patients had a normal response. Four (44\%) of 9 patients with a weight gain of greater than $20 \%$ after the operation showed endothelial dysfunction compared with none of the 10 patients with normal responses $(P<.04)$. The severity of the intimal thickness correlated with the years after transplant $(r=0.45, P<.05)$. Patients with endothelial dysfunction had more intimal thickening than those without $(32 \%$ $\pm 17 \%$ vs $17 \% \pm 12 \%$, respectively; $P<.05$ ). Furthermore, the degree of intimal thickening correlated with the magnitude of the vasomotor response to acetylcholine $(r=-0.60, P=.006)$. No relationship was found between intimal thickness and the vasodilatory response to nitroglycerin. As independent variables for intimal thickness, multivariate analysis detected the magnitude of the response to acetylcholine $(P=.0005)$, years after transplant $(P=.01)$, and ischemic time $(P=.03)$.

Conclusions: Cardiac allograft vasculopathy is a multifactorial disease the severity of which increases over time. Endothelial dysfunction is a predictive factor of intimal thickening severity. Predisposing factors that provoke endothelial injury, such as perioperative ischemic time and obesity, may contribute to the development of allograft vasculopathy.

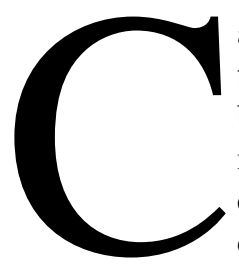

ardiac allograft vasculopathy is the main cause of morbidity and mortality after the first year of heart transplantation. ${ }^{1-3}$ Diagnosis on the basis of coronary angiography is limited to detect minimal or diffuse intimal thickening. Previous studies have demonstrated that intravascular ultrasonography (IVUS) is a sensitive technique for accurate detection of intimal thickening. ${ }^{4}$ The pathogenesis of allograft vascu- 
TABLE 1. Recipient and donor characteristics

\begin{tabular}{|c|c|c|c|c|}
\hline & $\begin{array}{l}\text { Overall } \\
(\mathrm{n}=19)\end{array}$ & $\begin{array}{l}\text { Normal vasomotor response } \\
\qquad(\mathrm{n}=10)\end{array}$ & $\begin{array}{l}\text { Endothelial dysfunction } \\
\qquad(\mathrm{n}=9)\end{array}$ & $P$ value \\
\hline \multicolumn{5}{|l|}{ Recipient variables } \\
\hline Age (y) & $52 \pm 11$ & $49 \pm 10$ & $53 \pm 11$ & NS \\
\hline Male/female ratio & $15 / 4$ & $7 / 3$ & $8 / 1$ & NS \\
\hline \multicolumn{5}{|l|}{ Diagnosis before heart transplant } \\
\hline Dilated cardiomyopathy & $15(79 \%)$ & $9(90 \%)$ & $6(67 \%)$ & \\
\hline Ischemic cardiomyopathy & $3(16 \%)$ & $0(0 \%)$ & $3(33 \%)$ & \\
\hline Valvular heart disease & $1(5 \%)$ & $1(10 \%)$ & $0(0 \%)$ & NS \\
\hline Mean blood pressure $(\mathrm{mm} \mathrm{Hg})$ & $109 \pm 11$ & $109 \pm 11$ & $110 \pm 6$ & NS \\
\hline Smoking & $1(5 \%)$ & $0(0 \%)$ & $1(11 \%)$ & NS \\
\hline Triglycerides (mmol/L) & $1.79 \pm 0.60$ & $1.56 \pm 0.47$ & $2.04 \pm 0.64$ & NS \\
\hline Cholesterol (mmol/L) & $6.19 \pm 0.98$ & $6.23 \pm 0.98$ & $6.16 \pm 0.76$ & NS \\
\hline Diabetes mellitus & $1(5 \%)$ & $1(10 \%)$ & $0(0 \%)$ & NS \\
\hline Obesity & $4(21 \%)$ & $0(0 \%)$ & $4(44 \%)$ & .04 \\
\hline No. of treated rejection episodes & $5.9 \pm 3.3$ & $6.50 \pm 3.98$ & $5.22 \pm 2.49$ & NS \\
\hline Cytomegalovirus infection & $4(21 \%)$ & $3(30 \%)$ & $1(11 \%)$ & NS \\
\hline Time after heart transplant (y) & $4.89 \pm 2.35$ & $5.40 \pm 2.80$ & $4.33 \pm 1.73$ & NS \\
\hline \multicolumn{5}{|l|}{ Donor data } \\
\hline Donor age (y) & $26 \pm 10$ & $25 \pm 9$ & $35 \pm 14$ & NS \\
\hline Male/female ratio & $9 / 10$ & $4 / 6$ & $5 / 4$ & NS \\
\hline Ischemic time (min) & $140 \pm 44$ & $134 \pm 37$ & $148 \pm 53$ & NS \\
\hline
\end{tabular}

$N S$, Not significant.

lopathy is not clearly elucidated, although it has been considered that early immunologic and nonimmunologic damage of the endothelium may initiate this process. ${ }^{5-8}$ Normal coronary arteries with intact endothelium vasodilate in response to arterial dilator agonists, such as acetylcholine, by stimulating the release of endothelium-derived relaxing factors, identified as nitric oxide. ${ }^{9}$ In patients with coronary artery disease and allograft vasculopathy, a paradoxical vasoconstrictor response to acetylcholine is commonly observed, indicating endothelial dysfunction. ${ }^{10-12}$ Whether the presence of endothelial dysfunction could predispose to the development of intimal thickening is controversial. ${ }^{13-20}$ To test the hypothesis that endothelial dysfunction is related to the degree of intimal thickening, we prospectively analyzed the vasomotor response to acetylcholine (vasodilator endothelium dependent) and nitroglycerin (vasodilator endothelium independent), as well as other donor and recipient variables. Findings were correlated with the intimal thickness, which was evaluated with IVUS.

\section{Methods \\ Patients}

Nineteen patients ( 15 men and 4 women; mean age, $52 \pm 11$ years; age range, 28-68 years) who had undergone orthotopic heart transplantation 1 or more years before the study (mean, $4.89 \pm 2.35$ years; range, 1-9 years) and who had angiographically normal coronary arteries and negative exercise thallium-201 perfusion scan results were included in the present study.
The study coincided with the routine annual angiographic examination; a clinical, echocardiographic, hemodynamic, and scintigraphic evaluation was undertaken. All patients had normal left ventricular size and ejection fraction, as well as cardiac index and end-diastolic left ventricular filling pressures. Concomitantly with the angiographic exploration, endothelial function and IVUS studies were performed. Recipient clinical variables included age, sex, diagnosis before heart transplantation, arterial blood pressure, obesity (weight gain after transplantation $>20 \%$ ), diabetes mellitus, plasma triglyceride and total cholesterol levels, number of treated biopsy-verified episodes of acute rejection during the first year, history of cytomegalovirus infection, and interval elapsed after heart transplantation. Donor variables were age, sex, and cold ischemia time (Table 1).

\section{Study Protocol of Endothelial Dysfunction}

Vasodilator drugs were discontinued at least 18 hours before cardiac catheterization. After completion of diagnostic catheterization, $5000 \mathrm{U}$ of sodium heparin was administered, and an $8 \mathrm{~F}$ Judkins catheter was positioned in the left coronary artery ostium. An angioplasty guide wire ( $0.014 \mathrm{inch}$ ) was advanced to the distal segment of the left anterior descending (LAD) coronary artery, and a $3 \mathrm{~F}$ infusion catheter was placed 0.5 to $1 \mathrm{~cm}$ distal to the origin of the first diagonal branch. The guide wire was removed. A series of sequential 3-minute intracoronary perfusions of 5\% dextrose and graded concentrations of acetylcholine $\left(10^{-6}, 10^{-5}\right.$, and $\left.10^{-4} \mathrm{~mol} / \mathrm{L}\right)$ and nitroglycerin $(40 \mu \mathrm{g} / \mathrm{mL})$ were then administered with a perfusion pump at a constant flow rate of $0.80 \mathrm{~mL} / \mathrm{min}$. A coronary angiogram was performed at the end of each perfusion. The presence of a normal vasomotor response was identified as an 


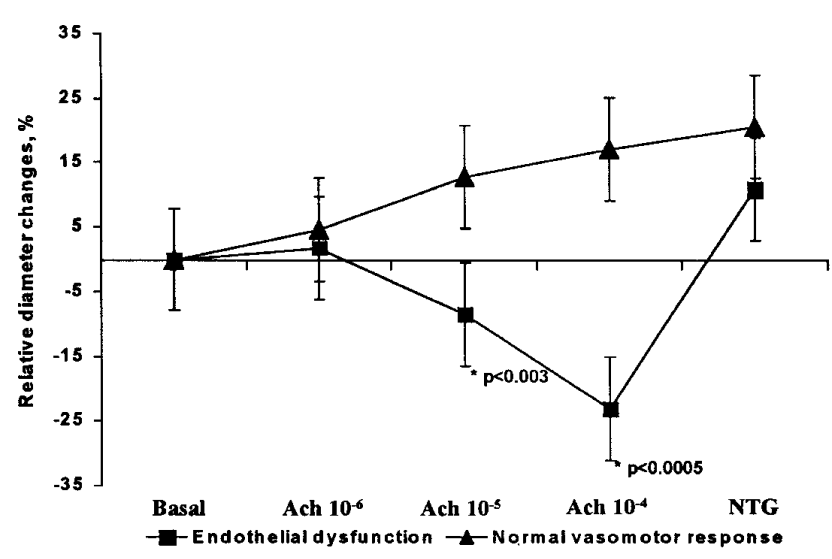

Figure 1. Plot of sequential changes in the coronary diameter after infusions of $5 \%$ dextrose (basal), graded acetylcholine (Ach), and nitroglycerin (NTG) in the distal LAD artery. Two patterns of vasomotor responses to acetylcholine were observed: a normal vasomotor response and a paradoxical vasoconstrictor response. *Statistical differences between patients with and without endothelial dysfunction.

increase in the coronary luminal diameter after perfusion of acetylcholine. Endothelial dysfunction was deemed to be present when a decrease in the coronary luminal diameter was detected.

\section{Quantitative Coronary Angiography}

Quantitative analysis of the coronary artery diameter was performed with a computer-assisted, automated, edge-contour detection system (Integris HM3000, Phillips Medical System, Leiden, The Netherlands) in the view that best allowed visualization of the LAD artery. After calibration of the arterial diameter with the Judkins catheter for reference, changes in the luminal diameter in response to vasoactive substances were evaluated. Measurements were performed on a 3- to 5-cm-long LAD segment approximately $2 \mathrm{~cm}$ distal to the tip of the perfusion catheter in an end-diastolic frame identified by a simultaneously recorded electrocardiogram.

\section{IVUS Imaging}

Nitroglycerin $(2 \mathrm{mg}$ ) was administered in the LAD artery after removal of the perfusion system and before IVUS. The imaging system comprised a $30-\mathrm{MHz}$ transducer enclosed within an acoustic housing on the tip of a $3.2 \mathrm{~F}$ catheter (CVIS Inc, Sunnyvale, Calif). The intracoronary imaging system was passed into the distal segment of the LAD artery over the 0.014 -inch guide wire. The pullback was initiated 4 to $6 \mathrm{~cm}$ distal from the origin of the first diagonal branch. The cross-sectional image with the highest intimal thickening was selected for measurement. Ultrasound images were recorded on videotape for further analysis.

The area of intimal thickening was calculated by planimetry, subtracting the cross-sectional area of the adventitial aspect of the intima from the cross-sectional area of the lumen. The result, the area of intimal thickening, was divided by the cross-sectional area of the adventitial aspect of the intima to obtain an intimal thickness index. ${ }^{15}$ This ratio was multiplied by 100 to reflect the percentage of the luminal obstruction caused by the intimal thickness.
Immunosuppression and Diagnosis of Allograft Rejection in Early and Late Stages of Follow-up All patients were managed with a standard 3-drug immunosuppressive regimen, including cyclosporine (INN: ciclosporin), azathioprine, and prednisone. The diagnosis of cardiac allograft rejection was made by means of histologic interpretation of endomyocardial biopsy specimens obtained during the first year of heart transplantation. The frequency of biopsies was one for the first 4 weeks, every 15 days until the third month, monthly from the third month to the sixth month, and then once each at 9 and 12 months. Classification of rejection was based on the recommendations of the International Society of Heart and Lung Transplantation. ${ }^{21}$ Decision to treat for acute rejection during the first year of transplantation was based on the detection of myocyte damage at biopsy. Treatment for rejection included a 3-day course of bolus of steroids plus antithymocytic globulin, followed by a control biopsy within 4 to 5 days after treatment. In this series an angiogram and thallium scintigraphy were performed annually.

\section{Statistical Analysis}

Changes in coronary diameter after acetylcholine or nitroglycerin infusions were expressed as a percentage of the luminal diameter during 5\% dextrose infusion. Unpaired $t$ tests and Fisher exact tests were used to assess differences between continuous and categorical variables. A correlation analysis was performed between the intimal thickening and other continuous variables of the donor and recipient. Multiple regression analysis with the stepwise procedure was used to identify independent variables related to the degree of intimal thickness. All data are expressed as means $\pm \mathrm{SE}$.

\section{Results}

Endothelium-dependent and Endothelium-independent Vasoreactivity of Coronary Arteries

During the perfusion of acetylcholine, $9(47 \%)$ patients had endothelial dysfunction, and the remaining 10 (53\%) patients had a normal vasomotor response. The decrease in coronary diameter in patients with endothelial dysfunction was $-23 \% \pm 19 \%$ compared with the control infusion (Figure 1). The increase in the coronary diameter with a normal vasomotor response was $17 \% \pm 11 \%(P<.005)$. After infusion of the endothelium-independent vasodilator nitroglycerin, patients with and without endothelial dysfunction reached a maximum vasodilatation of $10 \% \pm 9 \%$ and $23 \% \pm 20 \%$, respectively (not significant). Four (44\%) of 9 overweight patients had endothelial dysfunction compared with none of 10 patients with normal endothelial function $(P<.04)$. We did not find statistical differences in the remaining donor and receipt variables for the 2 groups of patients with and without endothelial dysfunction (Table 1). In addition, there was no relation between the nitroglycerin vasomotor response and any of the variables studied.

\section{Intimal Thickening and Receipt and Donor Variables}

In spite of the normal angiographic appearance of the coronary arteries, all patients demonstrated variable degrees of 


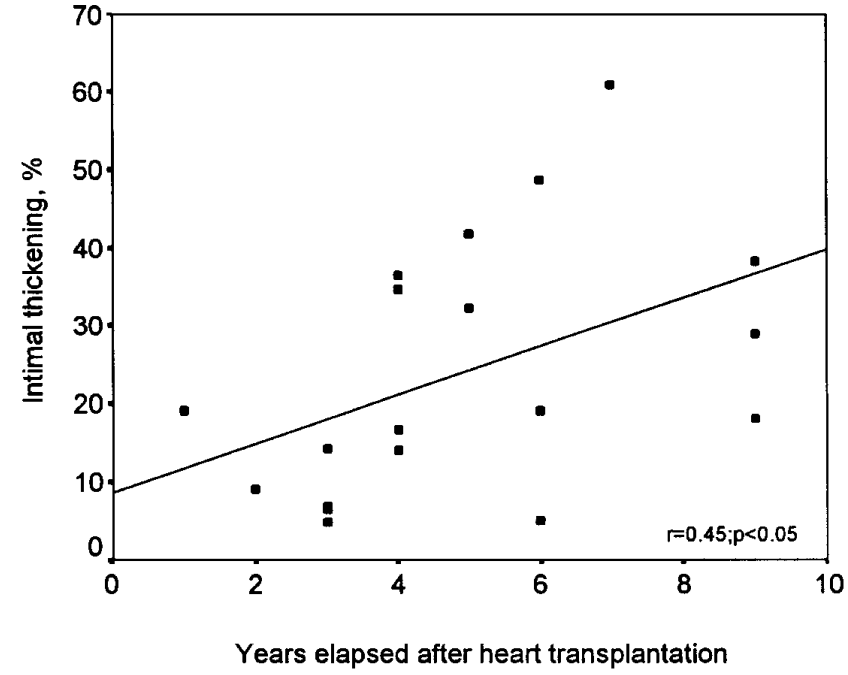

Figure 2. Scatterplot between the time elapsed after heart transplantation and intimal thickening evaluated by IVUS $(r=0.45$, $P<.05)$.

intimal thickening by IVUS (mean, $24 \% \pm 16 \%$; range, $5 \%$ $61 \%$ ). There was a correlation between the severity of the intimal thickness and the years after transplant $(r=0.45, P$ $<.05$; Figure 2). In 11 patients with an intimal thickening of less than $25 \%$, time from heart transplant was $4.0 \pm 2.2$ years. However, in 8 patients with an intimal thickening of $25 \%$ or greater, the time elapsed after operation was $6.1 \pm$ 2.0 years $(P<.05)$. We found no correlation between the degree of intimal thickness and the other recipient and donor characteristics analyzed.

\section{Intimal Thickening and Vasomotor Response to Acetylcholine and Nitroglycerin}

The group with endothelial dysfunction showed a greater intimal thickness index compared with those with a normal vasomotor response $(32 \% \pm 17 \%$ vs $17 \% \pm 12 \%, P<.05$; Figure 3). In addition, there was an inverse correlation between the intimal thickening and the magnitude of the coronary vasomotor response to acetylcholine $(r=-0.60, P$ $=.006$; Figure 4). No relationship was found between the degree of intimal thickness and the vasodilatory coronary response to nitroglycerin. Multiple regression analysis detected as independent variables related to the degree of intimal thickness and the magnitude of the vasomotor response to acetylcholine $(P=.0005)$, as well as time elapsed after heart transplant $(P=.01)$ and ischemic time $(P$ $=.03$, Table 2).

\section{Discussion}

The most acceptable mechanism of cardiac allograft vasculopathy is an immunologic mediated endothelial injury. ${ }^{6,7}$



Figure 3. Box plot showing more intimal thickening in heart transplant recipients with endothelial dysfunction than in those with a normal endothelial function $(P<.05)$.

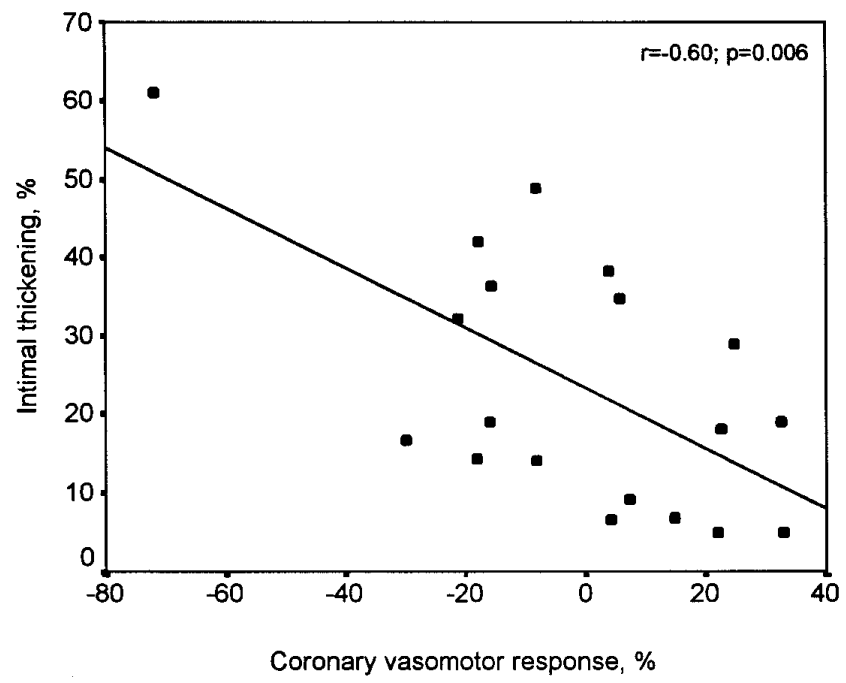

Figure 4. Scatterplot relating a significant inverse linear correlation between the vasomotor response to acetylcholine and the intimal thickening severity $(r=-0.60, P=.006)$.

Morphologic studies suggest that the functional and structural abnormalities of the endothelium precede the development of the atherosclerotic process. ${ }^{22,23}$ However, in the human patient neither angiography nor IVUS shows a clear relationship between the existence of an abnormal endothelial function and development of allograft vascular disease. ${ }^{11-20}$ In the present study we found that patients with endothelial dysfunction had a higher degree of intimal thickness than those without. Moreover, the magnitude of 
TABLE 2. Multiple regression analysis showing independent variables associated with intimal thickening

\begin{tabular}{|c|c|c|c|c|c|}
\hline & Unstandardized coefficients & Standard error & Standardized coefficients & $t$ & $P$ value \\
\hline Constant & 31.23 & 10.45 & - & 2.98 & .01 \\
\hline Magnitude of vasomotor response, $\%$ & -0.59 & 0.09 & -0.88 & -6.35 & .0005 \\
\hline Years elapsed after transplant & 2.66 & 0.96 & 0.34 & 2.75 & .01 \\
\hline Ischemic time (min) & 0.13 & 0.56 & 0.34 & 2.42 & .03 \\
\hline
\end{tabular}

the paradoxical vasomotor response to acetylcholine was more intensive the more severe the intimal thickness. In addition, in the multivariate analysis endothelial dysfunction emerged as an independent predictor variable of intimal thickening. These observations support an important role of endothelial dysfunction in the development of allograft vasculopathy. Using acetylcholine infusions to study the endothelial function, Davis and colleagues ${ }^{19}$ observed that coronary artery segments with early functional abnormalities had more intimal thickening by 1 year after transplantation than those with a normal endothelial function. However, using different methods, Julius and colleagues ${ }^{20}$ found no correlation between intimal thickening and vasodilatation induced by the exercise, which, when it is impaired, suggests endothelial dysfunction. The reasons for these discrepant findings are not clear. However, in addition to the differences in the methods, a likely explanation is the episodic nature of the immunologic injury and the reversibility of the endothelial dysfunction. ${ }^{19,24}$ Thus it has been reported that the endothelial function can normalize, even with the presence of intimal thickening. ${ }^{15}$ As seen in previous series, ${ }^{25}$ no relationship was found between the endothelium-independent vasodilator nitroglycerin and the variables studied (eg, degree of intimal thickness and time elapsed after the operation).

Several studies have shown those nonimmunologic factors, such as hypertriglyceridemia and pretransplant or posttransplant hypercholesterolemia may contribute to the development of allograft vascular disease. ${ }^{15,26-28}$ In the present study, using multivariate regression analysis, we found that the ischemic time is an independent predictor of intimal thickening. In accordance with our observation, experimental models have demonstrated that a prolonged ischemic time provokes vascular damage that contributes to the development of chronic rejection in the allograft. ${ }^{29}$ In a clinical study endothelial damage has been evidenced in distant donors with long ischemic times and may worsen after reperfusion. ${ }^{30}$ It has been observed that peritransplant ischemic injury may increase the risk of development of accelerated arteriosclerosis by 2.6 times. ${ }^{31}$

Weight gain leading to obesity is a common feature in heart transplant recipients and has been identified as a predictor of intimal thickening severity. ${ }^{26,28}$ In our patient pop- ulation we observed a significant relationship between weight gain and the presence of endothelial dysfunction. Although this association has been described in patients with insulin-resistance syndrome linked with obesity who have not undergone transplantation, ${ }^{32}$ to our knowledge, it has not been reported in heart transplant recipients. This suggests that the endothelial dysfunction associated with obesity may be an early manifestation of allograft vasculopathy. The modification of this cardiovascular risk factor by means of a hypocaloric diet and controlled exercise could improve the endothelial function and may prevent or delay the development of the allograft vasculopathy.

In accordance with other studies, ${ }^{4,33}$ we observed that all patients more than 1 year after the transplant operation had some degree of intimal thickening, as determined with IVUS. The disease initiates as early as 2 months after transplant, and the most rapid rate of progression occurs during the first year after heart transplant. It then follows a slow progression over time involving all the coronary segments. ${ }^{4,15,34}$ Using univariate analysis, Mehra and colleagues ${ }^{35}$ observed that the time elapsed from transplantation was longer in patients with severe intimal thickening than in those who showed minimal-to-moderate intimal thickening $(3.3 \pm 1.4$ vs $1.8 \pm 1.2$ years, $P<.01)$. Using correlation and multivariate analysis, we observed that intimal thickening is more severe the longer the time elapsed since heart transplantation, this being an independent predictor of intimal thickness severity.

The pathogenic mechanisms of cardiac allograft vasculopathy are poorly understood, but the hypothesis of the arteriosclerosis process postulated for the coronary artery disease in patients who have not undergone transplantation can be inferred to understand the accelerated arteriosclerosis disease in the cardiac allograft. ${ }^{36,37}$ According to this model, the endothelial injury caused by allograft rejection, peritransplant ischemia, and the traditional cardiovascular risk factors triggers a cascade of events that initiate allograft vasculopathy. These include reduction in the release of endothelium-derived relaxing factors, as an increase in platelet aggregation, and activation and adhesion of neutrophils to the lumen surface. The secretion of cytokines and growth factors is thus stimulated, promoting mononuclear infiltration and smooth muscle cell migration to the 
intima, as well as cellular proliferation with extracellular matrix accumulation. In obese patients it has also been suggested that the adipose cells may modulate the endothelium participating in this process by the secretion of cytokines. ${ }^{38}$ The worsening of the allograft vasculopathy observed over time is explained by endothelial injury caused by the sustained chronic rejection. Other cardiovascular risk factors may contribute further to the development of accelerated arteriosclerosis in patients undergoing heart transplantation.

The present study has some limitations that should be emphasized. First, our population represents a selected group of patients with angiographically normal coronary arteries. For safety reasons, IVUS was not performed in patients with angiographic evidence of allograft disease, small diameter of the LAD artery, or severe arterial tortuosity. Although complications during IVUS are rare, ${ }^{39}$ temporal occlusion of the vessel during IVUS pullback and severe coronary spasm caused by the rigidity of the catheter were the major concerns. In spite of this, a vasospasm with ST-segment elevation occurred in 2 patients, reverting with intracoronary nitroglycerin. We performed acetylcholine infusions in the LAD artery beyond the origin of the first diagonal branch to avoid a potential extensive vasoconstriction of the left coronary tree and to have a reference point to perform reproducible measurements in the same coronary segment in the group studied. However, this method has the disadvantage that the vessel diameter is too small to safely introduce an ultrasound catheter, especially when there is stenotic (focal or diffuse) allograft vasculopathy. Second, we evaluated the endothelial function and intimal thickening in only one coronary segment. However, because allograft vasculopathy is generally a diffuse disease, the other coronary segments likely have a similar response. Finally, although the data were collected prospectively, the design of the study is cross-sectional. The effects of the cumulative risk of other factors (eg, cholesterol and triglycerides) that may contribute to the intimal thickness are not therefore evaluated.

In conclusion, cardiac vascular allograft disease is a multifactorial entity, the severity of which increases over time. The observations from this prospective study suggest that endothelial dysfunction is a predictive factor of intimal thickening development. Reduction of endothelial injury by shortening the perioperative ischemic time and promoting weight loss may prevent or delay the development of cardiac allograft vasculopathy.

We thank Mrs Angeles Mañas for her assistance in the catheterization laboratory.

\section{References}

1. Uretsky BF, Murali S, Reddy PS, Rabin B, Lee A, Griffith BP, et al. Development of coronary artery disease in cardiac transplant patients receiving immunosuppressive therapy with cyclosporine and prednisone. Circulation. 1987;76:827-34.

2. Gao SZ, Alderman EL, Schoeder JS, Silverman JF, Hunt SA.
Accelerated coronary vascular disease in the heart transplant patient: coronary arteriographic findings. J Am Coll Cardiol. 1988;12:334-40.

3. O`Neill BJ, Pflugfelder PW, Singh NR, Menkis AH, McKenzie FN, Kostuk WJ. Frequency of angiographic detection and quantitative assessment of coronary arterial disease one and three years after cardiac transplantation. Am J Cardiol. 1989;63:1221-6.

4. St Goar FG, Pinto FJ, Alderman EL, Valantine HA, Shroeder JS, Gao SZ, et al. Intracoronary ultrasound in cardiac transplant recipients: in vivo evidence of "angiographically silent" intimal thickening. Circulation. 1992;85:979-87.

5. Brasile L, Zerbe T, Rabin B, Clarke J, Abrams A, Cerilli J. Identification of the antibody to vascular endothelial cell in patients undergoing cardiac transplantation. Transplantation. 1985;40:672-5.

6. Salomon RN, Hughes CC, Schoen FJ, Payne DD, Pober JS, Libby P. Human coronary transplantation-associated arteriosclerosis: evidence for a chronic immune reaction to activated graft endothelial cells. Am J Pathol. 1991;138:791-8.

7. Costanzo-Nordin MR. Cardiac allograft vasculopathy: relationship with acute cellular rejection and histocompatibility. J Heart Lung Transplant. 1992;11:S90-103.

8. Johnson MR. Transplant coronary disease: nonimmunologic risk factors. J Heart Lung Transplant. 1992;11:S124-32.

9. Amezcua JL, Dusting GJ, Palmer RM, Moncada S. Acetylcholine vasodilatation in the rabbit isolated heart through the release of nitric oxide, the endogenous nitrovasodilator. Br J Pharmacol. 1988;95:830-4.

10. Furchgott RF. Role of endothelium in responses of vascular smooth muscle. Circ Res. 1983;53:557-73.

11. Fish RD, Nabel EG, Selwyn AP, Ludmer PL, Mudge GH, Kirshenbaum JM, et al. Responses of coronary arteries of cardiac transplant patients to acetylcholine. J Clin Invest. 1988;8:21-31.

12. Ludmer PL, Selwyn AP, Shook TL, Wayne RR, Mudge GH, Alexander RW, et al. Paradoxical vasoconstriction induced by acetylcholine in atherosclerotic coronary arteries. N Engl J Med. 1986; 315:1046-51.

13. Mills RM Jr, Billett JM, Wilmer W, Nichols WW. Endothelial dysfunction early after heart transplantation. Assessment with intravascular ultrasound and Doppler. Circulation. 1992;86:1171-4.

14. Mügge A, Heublein B, Kuhn M, Nolte C, Haverich A, Warnecke J, et al. Impaired coronary dilator responses to substance $\mathrm{P}$ and impaired flow-dependent dilator responses in heart transplant patients with graft vasculopathy. J Am Coll Cardiol. 1993;21:163-70.

15. Anderson TJ, Meredith IT, Uehata A, Mudge GH, Selwyn AP, Ganz P, et al. Functional significance of intimal thickening as detected by intravascular ultrasound early and late after cardiac transplantation. Circulation. 1993;88:1093-100.

16. Heroux AL, Silverman P, Constanzo MR, O’Sullivan EJ, Johnson MR, Liao Y, et al. Intracoronary ultrasound assessment of morphological and functional abnormalities associated with cardiac allograft vasculopathy. Circulation. 1994;89:272-7.

17. Mügge A, Brandes RP, Heublein B, Nolte C, Haverich A, Lichtlen PR. Endothelial dysfunction in heart transplanted patients with graft vasculopathy. Eur Heart J. 1995;16(Suppl J):78-83.

18. Clausell N, Butany J, Molossi S, Lonn E, Gladstone P, Rabinovitch M, et al. Abnormalities in intramyocardial arteries detected in cardiac transplant biopsy specimens and lack of correlation with abnormal intracoronary ultrasound or endothelial dysfunction in large epicardial coronary arteries. J Am Coll Cardiol. 1995;26:110-9.

19. Davis SF, Yeung AC, Meredith IT, Charbonneau F, Ganz P, Selwyn AP, et al. Early endothelial dysfunction predicts the development of transplant coronary artery disease at 1 year posttransplant. Circulation. 1996;93:457-62.

20. Julius BK, Attenhofer Jost CH, Sütsch G, Brunner HP, Kuenzli A, Vogt PR, et al. Incidence, progression and functional significance of cardiac allograft vasculopathy after heart transplantation. Transplantation. 2000;69:847-53.

21. Billingham ME, Cary NRB, Hammond ME, Memmitz J, Marboe C, McCallister HA, et al. A working formulation for the standardization of nomenclature in the diagnosis of heart and lung rejection: heart rejection study group. J Heart Transplant. 1990;9:587-93.

22. Forbes RD, Guttman RD, Gomersall M, Hibberd J. A controlled serial 
ultrastructural tracer study of first-set cardiac allograft rejection in the rat: evidence that the microvascular endothelium is the primary target of graft destruction. Am J Pathol. 1983;111:184-96.

23. Young-Ramsaran JO, Hruban RH, Hutchins GM, Phelps TH, Baumgartner WA, Reitz BA, et al. Ultrastructural evidence of cellmediated endothelial injury in cardiac transplant-related accelerated arteriosclerosis. Ultrastruct Pathol. 1993;17:125-37.

24. Sabate M, Cequier A, Manito N, Mauri J, Roca J, Gomez-Hospital F, et al. Predictive factors and long-term evolution of early endothelial dysfunction after cardiac transplantation. J Heart Lung Transplant. 2000; 19:453-61.

25. Pinto FJ, St Goar FG, Fischell TA, Stadius ML, Valantine HA, Alderman EL, et al. Nitroglycerin-induced coronary vasodilation in cardiac transplant recipients: evaluation with in vivo intracoronary ultrasound. Circulation. 1992;85:69-77.

26. Escobar A, Ventura HO, Stapleton DD, Mehra MR, Ramee SR, Collins TJ, et al. Cardiac allograft vasculopathy assessed by intravascular ultrasonography and nonimmunologic risk factors. Am $J$ Cardiol. 1994;74:1042-6.

27. Mehra M, Ventura HO, Chambers R, Collins TJ, Ramee SR, Kates MA, et al. Predictive model to assess risk for cardiac allograft vasculopathy: an intravascular ultrasound study. J Am Coll Cardiol. 1995; 26:1537-44

28. Hauptman PJ, Davis SF, Miller L, Yeung AC. The role of nonimmune risk factors in the development and progression of graft arteriosclerosis: preliminary insights from a multicenter intravascular ultrasound study. J Heart Lung Transplant. 2000;14(Suppl):S238-42.

29. Yilmaz S, Paavonen T, Hayry P. Chronic rejection of rat renal allografts. II. The impact of prolonged ischemia time on transplant histology. Transplantation. 1992;S3:823-7.

30. Billingham ME, Baumgartner WA, Watson DC, Reitz BA, Masek M, Raney AA, et al. Distant heart procurement for human transplantation: ultrastructural studies. Circulation. 1980;62(Suppl):I-11-9.
31. Gaudin PB, Rayburn BK, Hutchins GM, Kasper EK, Baughman K, Goodman SN, et al. Peritransplant injury to the myocardium associated with the development of accelerated arteriosclerosis in heart transplant recipients. Am J Surg Pathol. 1994;18:338-46.

32. Steinberg HO, Chaker H, Leaming R, Johnson A, Brechtel G, Baron AO. Obesity/insulin resistance is associated with endothelial dysfunction: implications for the syndrome of insulin resistance. J Clin Invest. 1996;97:2601-10.

33. Rickenbacher PR, Pinto FJ, Chenzbraun A, Botas J, Lewis NP, Alderman EL, et al. Incidence and severity of transplant coronary disease early and up to 15 years after transplantation as detected by intravascular ultrasound. J Am Coll Cardiol. 1995;25:171-7.

34. Yeung AC, Davis SF, Hauptmann PJ, Kobashigawa JA, Miller LW, Valantine HA, et al. Incidence and progression of transplant coronary artery disease over 1 year: results of a multicenter trial with use of ultravascular ultrasound. J Heart Lung Transplant. 1995;14:S215-20.

35. Mehra MR, Ventura HO, Stapleton DD, Smart FW, Collins TC, Ramee SR. Presence of severe intimal thickening by intravascular ultrasonography predicts cardiac events in cardiac allograft vasculopathy. J Heart Lung Transplant. 1995;14:632-9.

36. Ross R. Pathogenesis of atherosclerosis: an update. $N$ Engl J Med. 1986;314:488-91.

37. Ip JH, Fuster V, Badimon L, Badimon J, Taubman MB, Chesebro JH. Syndromes of accelerated atherosclerosis: role of vascular injury and smooth muscle cell proliferation. J Am Coll Cardiol. 1990;15: 1667-87.

38. Yudkin JS, Stehouwer CD, Emeiss JJ, Coppack SW. C-reactive protein in healthy subjects: associations with obese-insulin resistance, and endothelial dysfunction: a potential role of cytokines originating from adipose tissue? Arterioscler Thromb Vasc Biol. 1999;19:972-8.

39. Hausmann D, Erbel R, Alibelli-Chemarin MJ, Boksch W, Caracciolo E, Cohn JM, et al. The safety of intracoronary ultrasound: a multicenter survey of 2207 examinations. Circulation. 1995;91:623-30.

\section{Targeted}

The Journal of Thoracic and Cardiovascular Surgery gives you two tables of contents.

The condensed table of contents tells you at a glance what topics and authors are presented each month. The expanded table of contents gives you a brief abstract of each article. You select only those articles of most interest to you for further reading. 